\title{
The East African Monetary Union: Is the Level of Business Cycle Synchronization Sufficient?
}

\author{
William Miles ${ }^{1}$ \\ ${ }^{1}$ Department of Economics, Wichita State University, Wichita, Kansas USA \\ Correspondence: William Miles, 1845 Fairmount, Wichita, KS 67260-0078, USA
}

Received: September 14, 2015

Accepted: September 28, 2015

Available online: October 9, 2015

doi:10.11114/aef.v2i4.1134

URL: http://dx.doi.org/10.11114/aef.v2i4.1134

\begin{abstract}
The East African Community (Burundi, Kenya, Rwanda, Tanzania and Uganda) has a goal of a currency union, as part of a movement toward eventual political union. A key factor in making a currency union desirable is a high level of business cycle synchronization (BCS) among member countries. In this paper we undertake a new approach to this topic with a recently developed set of tools. These tools have the advantage of yielding time-varying estimates, and, unlike previous metrics, allow us to gauge both differences of the phase of the business cycle between countries and differences in business cycle amplitude. We find BCS among the five countries does compare reasonable well with that found for euro zone nations before euro adoption. However, given the euros' difficulties, this is not strong evidence in favor of the desirability of a currency union. Moreover, Rwanda appears less well-suited, in terms of BCS, than the other four countries. In addition, all five nations have experienced sharp drops in BCS in recent years. Lastly, there has been no significant increase in BCS since the 2000 EAC Treaty, or the 2005 customs union. Overall, our results cast doubt on the desirability of an East African currency union.
\end{abstract}

Keywords: currency union, optimal currency area, east Africa, business cycle synchronization

\section{Introduction}

The East African Community (EAC) was created through a treaty, signed in November 1999 by officials from Kenya, Tanzania and Uganda (Burundi and Rwanda would eventually sign on as well) which called for the establishment of a monetary and eventually political union among the five nations. Along the path to a common currency, a customs union among the EAC nations was created in 2005. The currency union (CU) was scheduled to begin in 2012, and of course that target has been missed. However, monetary union for the EAC countries is still an objective.

There are a number of legitimate concerns over a possible CU for these countries. A set of criteria for deciding whether a group of countries should drop their own currencies and form a monetary union was first formally put together in the Optimal Currency Area (OCA) literature started by Mundell (1961). Nations that engage in high levels of trade, and have easy labor mobility between them may stand to benefit from a CU. However, there are also costs to a monetary union-each country gives up the ability to use nominal exchange rate depreciation and independent monetary policy to adjust to possible asymmetric shocks. It is therefore desirable that the member countries in a CU have a high level of business cycle synchronization (BCS).

The euro zone provides something of a cautionary tale regarding a CU in which there is insufficient BCS. In the early years of the euro, capital flowed from slow-growing "center" nations to smaller, "peripheral" countries, fueling growth, as well as credit and housing bubbles in the latter. Since the financial crisis of 2007-08, these bubbles have burst, leading to unemployment of over $25 \%$ in nations such as Greece and Spain, while growth in Germany, the euro zone's largest economy, remains positive. And despite vast differences in business cycles over the last decade, the smaller euro countries cannot use nominal depreciation, as they have no currencies of their own to depreciate. There have also been complaints that the ECB has run an excessively tight monetary policy (it famously raised interest rates in 2011 in the midst of deep recessions among smaller euro members), while on the other hand officials in Germany, such as prime minister Angela Merkel and Bundesbank President Jens Weidmann, have criticized the ECB for being too loose. Thus a $\mathrm{CU}$ in which member countries have divergent business cycles is inherently problematic.

Accordingly, several studies have been conducted on the feasibility of the EAC monetary union. Papers such as Mkenda (2001), Buigut and Valev (2005), and Kishor and Ssozzi (2011) have addressed the issue of the suitability of monetary 
union among EAC countries. As will be discussed, there are some methodological issues concerning each paper.

Another issue is that a full picture of BCS among these African nations has not been addressed thus far. Previous papers have employed correlation-based measures of BCS, which could give a very misleading gauge of how connected output gaps in different countries are. Mink, Jacobs and DeHaan (2012) explain that two countries could have the signs of their output gaps highly correlated but could also have very large differences in output amplitude (see Figure 1, largely adopted from Mink, et al.).

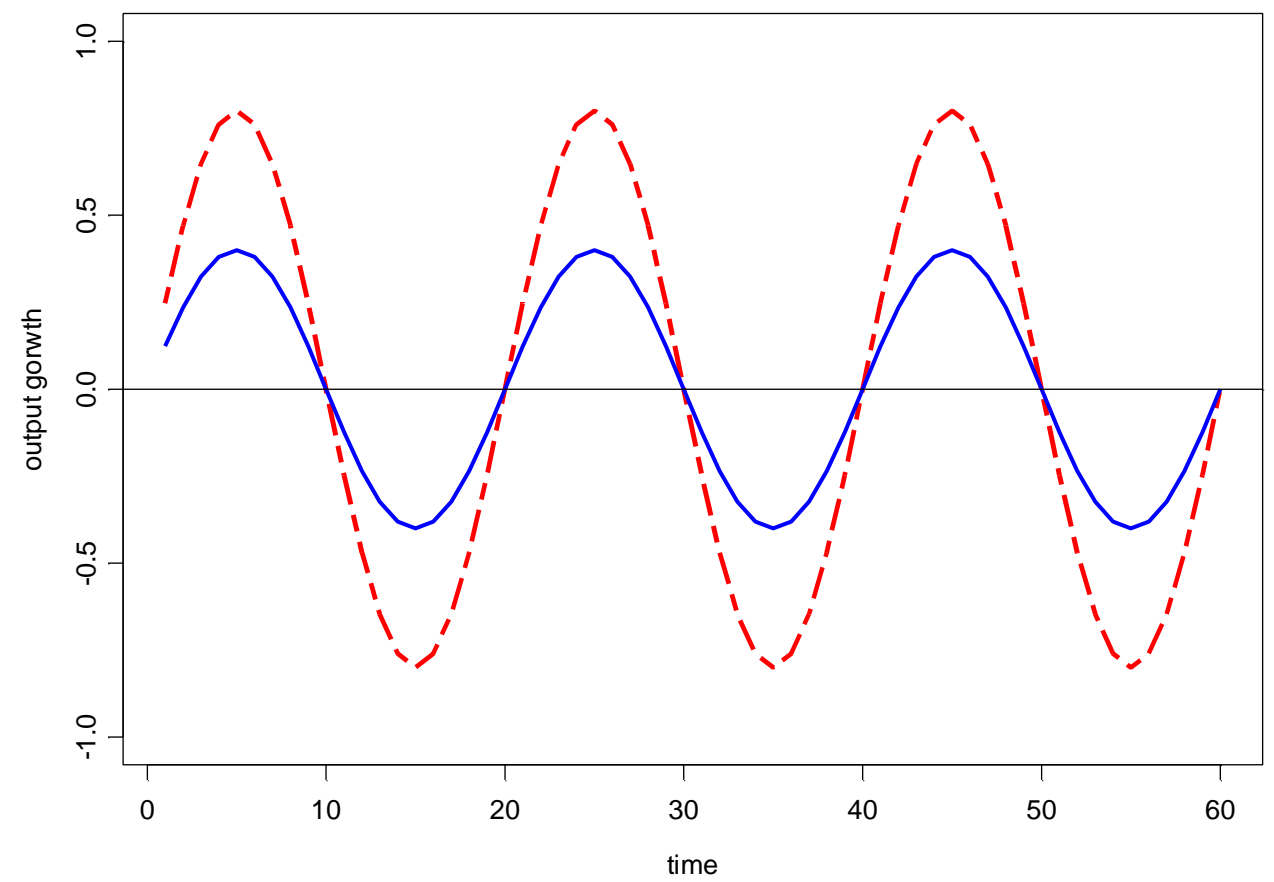

Figure 1. Hypothetical Business Cycles for Two Countries

We will thus apply the Mink, et al. method to the potential EAC monetary union. The estimates will yield time-varying measures that will help us discern the path of BCS over time. This will allow us to examine the impact of policy changes such as the 2000 EAC Treaty on BCS. This latter issue addresses the "endogenous OCA" theory of Frankel and Rose (1996). These authors posit that countries that do not appear ready for a CU due to low BCS may be made ready by the vary act of joining-this is owing, in the authors' reasoning, to a common currency greatly increasing trade, and the higher trade then increasing BCS. We will investigate this issue with formal tests of structural change in our time-varying BCS measure, something not yet done in the literature.

To anticipate our results, we find that the BCS measures for the five nations compare reasonably favorably to those of euro zone nations prior to the creation of the euro. However, this is hardly a reason to abandon concerns over the EAC $\mathrm{CU}$ as the euro zone continues to exhibit great adjustment difficulties. We also find that the individual countries have had major declines in BCS during some recent years, even after the 2000 EAC Treaty and 2005 customs union. In addition, Rwanda appears to have lower BCS with the EAC than its neighbors, even after allowing for the years of civil war and genocide. Finally, we find a failure of the 2000 treaty and 2005 customs union to increase BCS significantly, which casts doubt on the Frankel-Rose hypothesis of trade increasing BCS, as well as casting doubt on the feasibility of the EAC CU.

This paper proceeds as follows. The next section details the background and previous literature. The third section describes the data and methodology. The fourth section explains our results, and the fifth section concludes.

\section{Background and Previous Literature}

In November 1999, the East African Community (EAC) was founded by a treaty among Kenya, Tanzania and Uganda. Later, in 2007, Burundi and Rwanda also joined the EAC. The treaty contained several long-range goals. First, a customs union was to be formed among the member countries-this was accomplished in 2005. A common market, with free factor mobility, was to begin in 2015. Eventually, the nations were to form a CU. The goal had been to create the monetary union by 2012, although the date for this goal was at first missed. A CU still remains an objective; furthermore, political union has been stated as an ultimate goal (United Nations, 2011).

The CU among the five nations may bring both benefits as well as costs. The formal analysis of whether a set of 
countries would form an "Optimal Currency Area" goes back to Mundell (1961). According to Mundell, if there is a high level of trade among a group of countries, they may benefit from the lower transactions costs resulting from a single money. The mobility of labor is also held to be important for the workability of a monetary union.

Fiscal transfers among different nations would also help make a CU feasible (this is likely true of the different states and regions of the United States "dollar zone"-states suffering hard economic times can send less and receive more from the federal government than in good times). Later research has focused on business cycle synchronization (BCS) as an important criteria for whether nations should join a CU. If one country in the monetary union is going through an inflationary boom, while another is in a deep recession, a nominal depreciation of the latter's currency is not possible as a way to make growth rates more equal once a $\mathrm{CU}$ is in place. Moreover, the latter nation would likely benefit from loose monetary policy, while the former would be best served with tighter monetary conditions. But of course within a CU two different monetary policies are not possible. Thus BCS is an important criteria in making a CU truly optimal.

Some later papers have suggested that a low level of BCS within a set of prospective CU countries may not necessarily be a cause for much concern. According to this research (Frankel and Rose, 1996), the level of trade, as well as BCS, are endogenous with respect to the existence of the CU. That is, trade, as well as BCS, may palpably rise once a CU is created compared to their levels when member countries still had their own currencies. Frankel and Rose refer to this idea of an "endogenous OCA". The authors believe that a common currency will have a large effect on the level of trade (by their initial estimates, a CU may triple trade). More trade would then lead to greater BCS.

Both claims-that a monetary union would have a very large effect on trade, and that greater trade would increase BCS, have been called into question by a number of subsequent studies. To take just two examples, Persson (2001) and Wolff and Ritschl (2011) present results suggesting little, if any effect of common currencies on trade. Moreover, the notion that higher trade would raise BCS is not immediately clear intuitively. Basic trade models by Ricardo and Hecksher and Ohlin would suggest that greater trade would lead to greater specialization, leading to more asymmetric reactions to shocks and less, rather than more BCS. Indeed several papers (Miles and Vijverberg, 2014, Willett, Permpoon and Wihlborg, 2010) have cast doubt on the "synchronizing" properties of rigid exchange rate regimes or common currencies. We will examine whether greater ease of trade has improved BCS among the five EAC nations; to anticipate our findings the results provide little support for the synchronizing effects of greater trade.

There have been several studies to date on whether the five EAC nations may be an OCA. Mkenda (2001) examines whether Purchasing Power Parity (PPP) exists among the countries of Kenya, Tanzania and Uganda. The author finds that there is long run PPP among these three countries insofar as there is cointegration among their real exchange rates. The author interprets this as evidence in favor of the desirability of a $\mathrm{CU}$ among these nations. However, it should be noted that even if PPP were to prevail over time, deviations in the short run could still lead to pronounced and persistent misalignments, which could make a CU difficult without the availability of nominal adjustment. In addition, Xu (2006) notes that exchange rates as well as some prices were subject to government controls, so that caution in making inference on PPP is warranted.

Employing an alternative approach, Buigut and Valev (2005) gather annual data on output and prices for the 1970-2001 period for all five EAC nations. The authors employ Vector Autoregression (VAR) analysis, and impose identifying restrictions on the parameters to obtain estimates of demand and supply shocks. The authors find a high degree of asymmetry in the shocks, which would make a CU among the five countries difficult.

Kishor and Ssozzi (2011) employ annual data on output and inflation running from 1970 through 2007. The authors, like Buigut and Valev, employ Blanchard-Quah decomposition in a VAR. They criticize Buigut and Valev's technique, however, for ignoring a possible common factor which may drive economic activity in all five economies as well as for not allowing for time-varying estimates so that the evolution of BCS can be observed over time.

The authors thus obtain supply and demand shock estimates for the five countries, and compute correlations to see how synchronized the shocks appear across the nations. The results vary, but in some cases the estimated correlations are negative, which would augur poorly for the prospects for a CU. To see how much influence a common factor may have the authors estimate a state space model in which the shocks are decomposed into country-specific and common components. The authors find that the common component explains a relatively small portion of the overall variability of demand and supply shocks (at most about 36 percent, in one case less than one percent) compared to country-specific forces. This suggests a CU could be problematic among these nations. Finally, to see how BCS may have changed through time, after, for instance the 2000 EAC Treaty, the authors regress the common component of demand shocks on each nations demand shocks. They obtain time-varying estimates, and find that these time-varying parameter estimates appear to rise through time for Tanzania, and do show a marked increase for Kenya since the 2000 EAC Treaty. However, these time-varying estimates do not appear to rise through time for the other three EAC countries.

Kishor and Ssozzi have made a very key contribution-obtaining time-varying estimates of BCS is important, especially 
if there have been major changes regarding trade or other economic policies which may have an impact on the effect of a common currency. There are some issues of interpretation, however. The method of Blanchard and Quah decomposition to identify shocks can be very "fragile", and yield results which are not what the author is intending to measure. For instance, Bayoumi and Eichengreen (1992) employ this technique to identify shocks and assess the impact of exchange rate arrangements such as the gold standard. However, Von Hagen and Neumann (1994) note that the authors had incorrectly identified shocks with this method. In addition, of course, the authors cannot distinguish between differences in the phases of business cycles and differences in the amplitude between different countries (Mink, 2012). Accordingly, we will employ a less fragile, recently developed set of tools that have been utilized to assess BCS in the Euro currency area.

\section{Method}

\subsection{Data}

Data on output was obtained from the Penn World Table (PPP converted GDP) for the five nations, running from 1960 through 2010. This runs for several years after the sample of previous studies to allow more inference on the effect of changes such as the EAC Treaty.

\subsection{Importance of Time-Varying Estimates and De-Trending Variables}

Some previous papers on the East African CU have estimated only one measure of BCS for the entire sample (Kishor and Ssozi are a notable exception, as they employ time-varying methods to assess the impact of the 2000 EAC Treaty on BCS for the five nations). Discerning how BCS evolves through time can shed light on whether, per the "endogenous OCA" theory of Frankel and Rose, trade may increase BCS. In addition, we have noted that techniques employed in previous papers may lead to fragile and questionable estimates, and do not allow for assessing differences in the signs of business cycles versus differences in amplitude.

This is, as Mink, et al. (2012) explain, an important issue in discerning the true level of integration of output gaps. Figure 1 (largely adopted from Mink, et al.) displays output gaps for two hypothetical nations. If one examined measures that were based purely on correlation, one would conclude that the two nations had very high levels of BCS (indeed their business cycles would appear identical) making a CU appear very feasible.

Unfortunately, if the two countries in Figure 1 went ahead and formed a monetary union, Country 1(represented by the dashed line) would desire a much tighter monetary policy in a boom than Country 2; moreover, in a downturn, Country 1 would prefer a much looser monetary policy than Country 2. And of course, in a CU, at least one, if not both countries will be disappointed that monetary policy will not be optimal for their specific circumstances.

Mink, et al. emphasize that previous papers do not distinguish between these important differences in the sign of output gaps versus differences in amplitude, and note that in a CU differences in amplitude will cause difficulties in forming an "optimal" monetary policy.

Mink, et al. accordingly developed metrics that gauge both whether nations are in the same phase of the business cycle as well as differences in the amplitude of cycles. They applied these measures to Europe, as BCS (or the lack thereof) is an important topic for the Euro common currency.

The first step is to de-trend the GDP data to obtain stationary series. The Christiano-Fitzgerald (CF) filter is employed, as Mink, et al. quote Koopman and Aceveda (2008) who state that the CF filter is the "best performing and most flexible linear filter available" (Mink, et al. p. 220). Having employed the CF filter to decompose each country's GDP into a trend and deviation, we will follow Mink, et al. and define each nations' business cycle as the deviation divided by the corresponding trend. For notation, we will denote the cycle, or output gap for country i in period $\mathrm{t}$ as $g_{i}(t)$. To assess BCS, there will be a "reference" cycle. The reference cycle is denoted as $g_{r}(t)$.

\subsection{Business Cycle Synchronization Measures}

The first BCS measure is called synchronicity. It is denoted as:

$$
\varphi_{i r}(t)=\left(g_{i}(t) g_{r}(t)\right) /\left(\left|g_{i}(t) g_{r}(t)\right|\right)
$$

This metric tells us whether country $i$ and the reference are in the same phase of the business cycle. If they are indeed in the same phase, synchronicity yields a value of +1 for period $t$. If country $i$ is in recession while the reference is in expansion (or vice-versa) then synchronicity has a value of -1 . One can obtain an aggregate, overall measure of synchronicity for a given set of countries with the following:

$$
\varphi(t)=(1 / \mathrm{n}) \sum_{i=1}^{n} \quad\left(g_{i}(t) g_{r}(t)\right) /\left(\left|g_{i}(t) g_{r}(t)\right|\right)
$$


This overall measure averages synchronicity for the $\mathrm{n}$ sample nations at time $\mathrm{t}$. This metric will range in value from 0 to +1 . If the value in a period is positive one, this means that all the countries in the sample are in the same phase of the business cycle.

The synchronicity measure does yield an estimate for each period, unlike some other previously employed metrics which give only one estimate for an entire sample. It does not, however, capture differences in amplitude. Mink, et al. refer to Figure 1 and note that differences in amplitude are very important for getting a fuller assessment of BCS. Accordingly, the authors developed another measure, called similarity, which can capture differences in amplitude. Similarity is denoted and calculated as:

$$
\gamma_{i t}(t)=1-\left(\left|g_{i}(t)-g_{r}(t)\right|\right) / \sum_{i=1}^{n}\left|g_{i}(t)\right| / \mathrm{n}
$$

Similarity is defined on the [1-n, 1] range-a value of 1 means country $i$ and the reference have identical business cycles. As with synchronicity, we can obtain an overall aggregate measure of similarity for a group of countries:

$$
\left.\gamma(t)=1-\left(\sum_{i=1}^{n}\left|g_{i}(t)-g_{r}(t)\right|\right) / \sum_{i=1}^{n}\left|g_{i}(t)\right|\right)
$$

This overall measure ranges from zero to one, with a value of +1 indicating all countries in the sample have identical business cycles.

There are a number of options for choosing the reference cycle. We follow Mink et al. and use the median gap from the sample as the reference.

\section{Results}

The aggregate measures of synchronicity and similarity are shown in Figure 2. Note that Mink, et al. obtained eight-year moving averages for their data. These authors had quarterly data running over thirty six years, so employing an eight-year moving average was feasible in their case. Our data is annual, as was the case for the papers of Kishor and Ssozi (2011) as well as Buigut and Valev (2005), so using moving averages would cost us much of our sample. We accordingly work with the un-averaged sample.

From Figure 2, we can observe that, on the whole, the aggregate measures compare reasonably favorably with the results of Mink, et al. and their aggregate measures for the euro zone (see Figure 4 in Mink, et al. 2012). Of course, given the Euro zone's difficulties, such as unemployment over $25 \%$ in some peripheral Euro zone members, this is not especially encouraging. In addition, there does not appear to be a steady positive progression in these measures, as will be formally confirmed for similarity with our break tests. Both synchronicity and similarity have sharp drops in 2008, although they subsequently recover. 


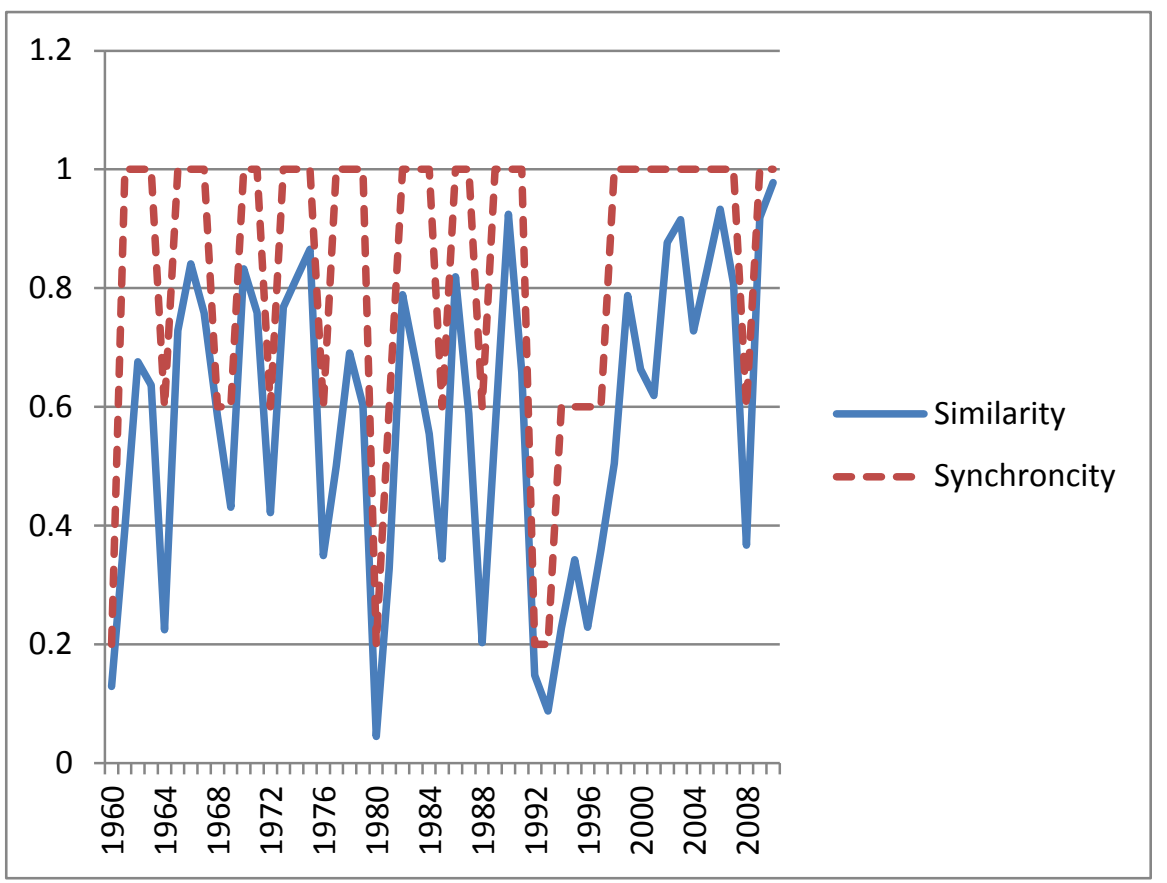

Figure 2. Aggregate Similarity and Synchronicity for the all five EAC nations

Summary statistics for the synchronicity and similarity measures for the five individual countries are displayed in Tables 1 and 2. In terms of ranking the countries by BCS, the synchronicity measure would indicate Tanzania as the most integrated, followed by Uganda, Kenya, Burundi and then Rwanda. However, as an indication that synchronicity is not an all-encompassing metric, missing as it does differences in amplitude, Table 2 shows that Kenya- $3^{\text {rd }}$ highest in BCS by synchronicity-has the highest similarity average. Tanzania, Burundi and Uganda are in second, third and fourth place. Overall, the results for synchronicity and similarity are somewhat different. For both measures, however, Rwanda displays the least BCS. Examining Figure 5, Rwanda had a huge drop in similarity throughout the 1990s and negative values for this measure until 1997. It is possible that the Rwandan civil war and subsequent political turmoil and genocide had a negative effect on BCS with other East African nations. However, when the years 1992-1997 are dropped from Rwanda's similarity results, the average for this measure is only 0.45 , which is still the lowest mean value among the five countries. This raises the question as to whether Rwanda is best suited by joining an eventual CU among the EAC nations.

Table 1. Synchronicity Results

\begin{tabular}{ccccccc}
\hline & Burundi & Kenya & Rwanda & Tanzania & Uganda & Overall \\
\hline Mean & 0.803 & 0.882 & 0.568 & 1 & 0.921 & 0.835 \\
SD & 0.6 & 0.475 & 0.83 & 0 & 0.392 & 0.255 \\
Max & 1 & 1 & 1 & 1 & 1 & \\
Min & -1 & -1 & -1 & 1 & -1 & \\
\hline
\end{tabular}

Whatever the existing level of BCS at a given time, it may be, according to the endogenous OCA Theory of Frankel and Rose, that the act of creating a CU among the EAC nations may increase BCS by boosting trade. We cannot yet know what the impact of such a CU on trade would be, as it has not yet been formed (moreover, whether a CU would increase trade palpably has been called into question; see the aforementioned Persson (2001) and Wolff and Ritschl (2011) as well as Havranek (2010)). However, the creation of the EAC in 2000 has been the subject of analysis by Kishor and Ssozi, who found that BCS, as measured by their time-varying regression results, appeared to be rising for Tanzania toward the end of the sample and particularly for Kenya since the 2000 treaty, but not for the other three EAC nations.

Table 2. Similarity Results

\begin{tabular}{ccccccc}
\hline & Burundi & Kenya & Rwanda & Tanzania & Uganda & Overall \\
\hline Mean & 0.661 & 0.699 & 0.249 & 0.692 & 0.621 & 0.584 \\
SD & 0.351 & 0.346 & 0.822 & 0.348 & 0.373 & 0.256 \\
Max & 1 & 1 & 1 & 1 & 1 & \\
Min & -0.399 & -0.693 & -2.056 & -0.738 & -0.252 & \\
\hline
\end{tabular}


In addition to the 2000 treaty, the five nations formed a customs union in 2005, as a precursor to eventual monetary union. We can examine our measures of synchronicity and similarity, just as Kishor and Ssozi displayed their time-varying regression estimates, to see if there was any notable increase in BCS following these policy changes. We will also go beyond informal observation and conduct formal tests for structural breaks in the similarity series, as did Mink, et al. (2012).

Looking first at the aggregate measures in Figure 2, synchronicity may seem somewhat higher since the mid-to-late 1990s, although there is a drop in 2008. Similarity more clearly does not exhibit an increase with time. If one restricts the sample to the post-1993 years, similarity appears to have an upward trend, but overall there is no palpable increase, and a notable downturn, as there was for synchronicity, in 2008. In addition, a regression of overall similarity on a time trend, to be explained below, led to an insignificant coefficient on the trend.

Turning next to the individual countries in Figures 3 through 8, Burundi does not show much pattern in either synchronicity or similarity. As was the case for the aggregate measures, both metrics experience a decline in 2008. For similarity, this decline is the sharpest of any drop in the country's sample.

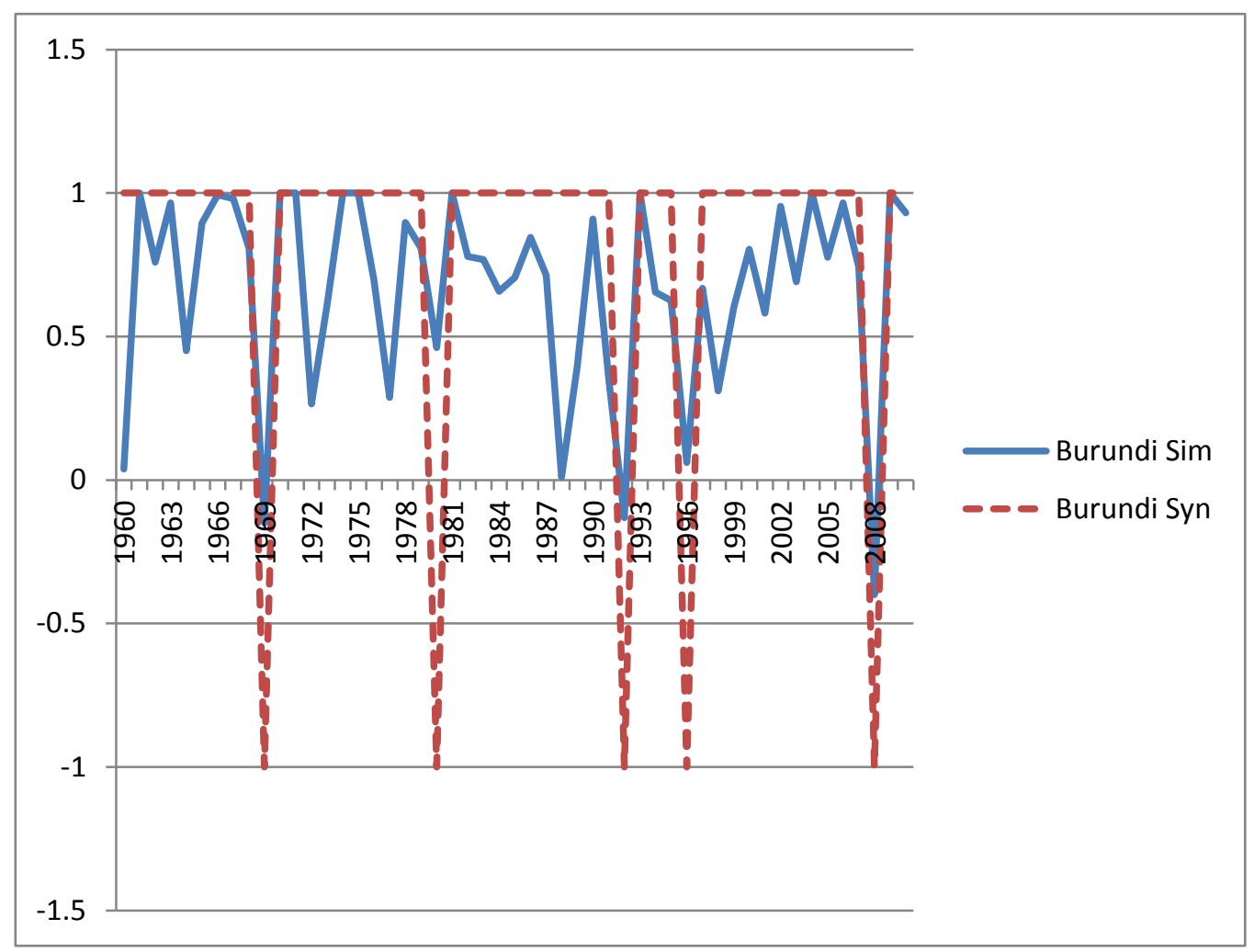

Figure 3. Similarity and Synchronicity for Burundi

Kenya's synchronicity has been high since the mid-1990s, although there has been no significant change in similarity. Synchronicity for Rwanda has been +1 since the late 1990s, which might be taken as some tentative evidence in favor of the notion that the EAC Treaty of 2000 or the customs union begun in 2005 may have improved BCS. However, Rwanda's similarity shows no such increase. In addition, the BCS for Rwanda is overall the lowest of any of the five EAC nations, and its improvement from the 1990s may well be due to the end of the civil war and genocide more so than the policy changes in the EAC. 


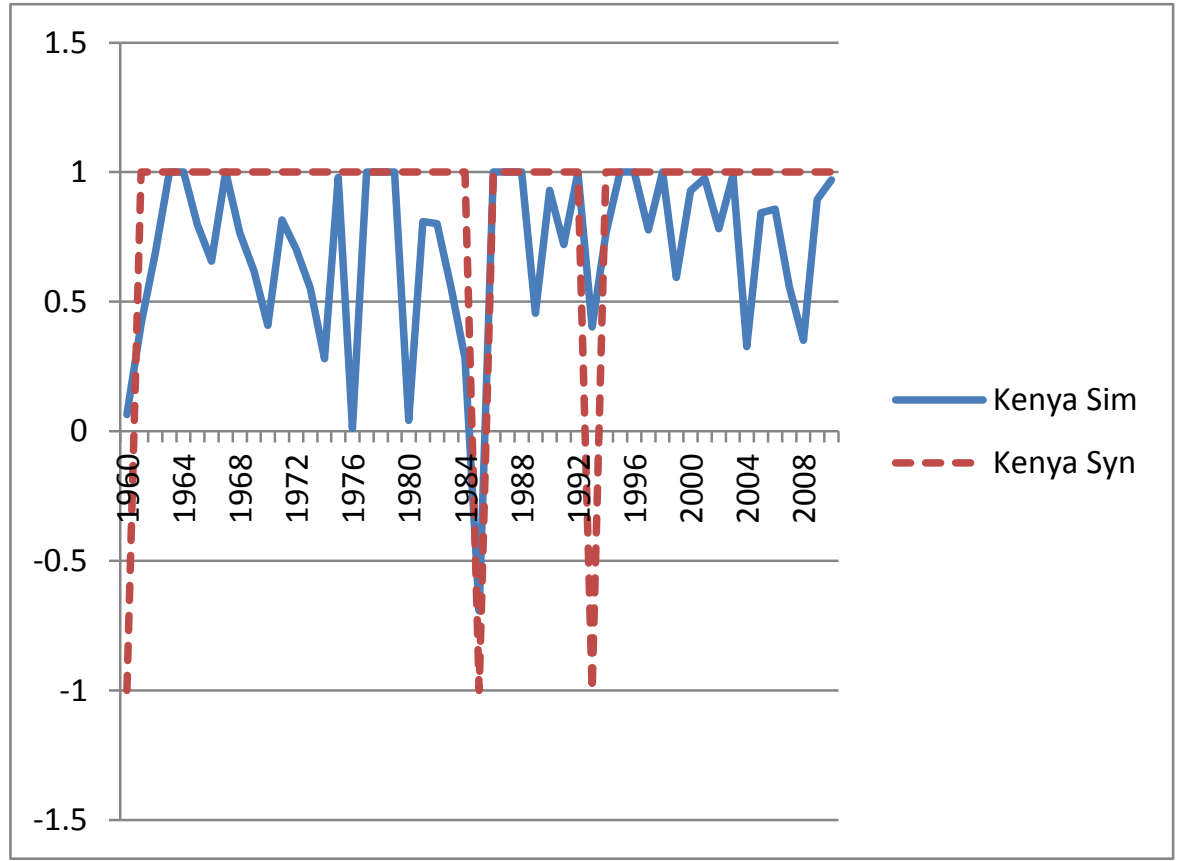

Figure 4. Similarity and Synchronicity for Kenya

Tanzania's synchronicity is, as is obvious from Figure 7 always positive, and of course therefore shows no change. Similarity does not appear to have an upward trend, and as is the case for many of these measures, shows a clear drop in 2008. Uganda's synchronicity was high for most for the sample, being +1 since 1993, well before and after 2000 (and 2005). Similarity fails to exhibit a pattern as well.

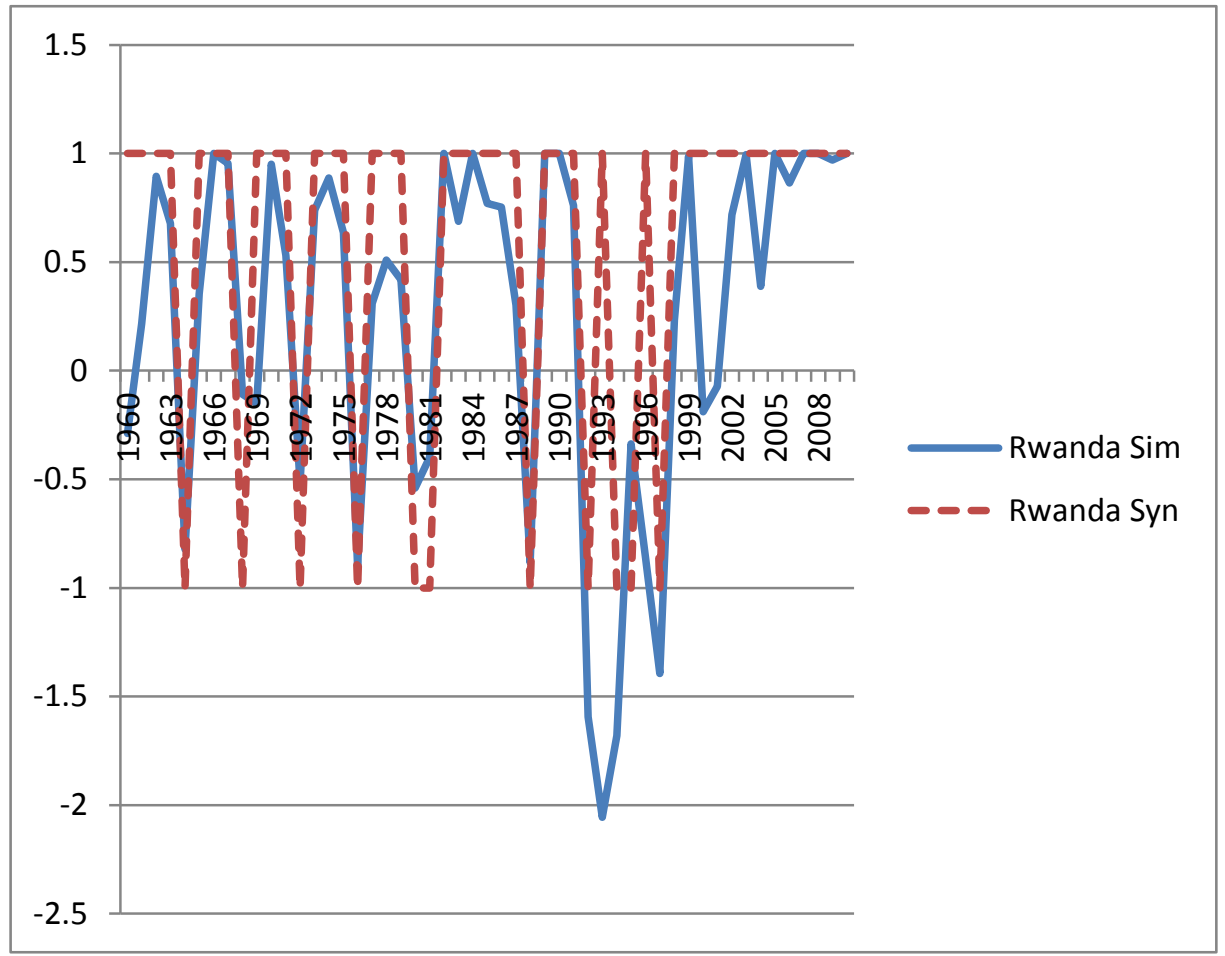

Figure 5. Similarity and Synchronicity for Rwanda

Examining synchronicity and similarity in this fashion does not constitute formal hypothesis testing. We could regress our similarity measure on dummy variables for the years after 2000, or 2005, and perform a Chow test for a structural break. However, testing for a break in this fashion, by choosing the date of the break based on knowledge of economic events will bias the procedure in favor of finding a "significant" change (when using standard t, F, or Chi-Square critical values) even when such a change has not actually occurred. 


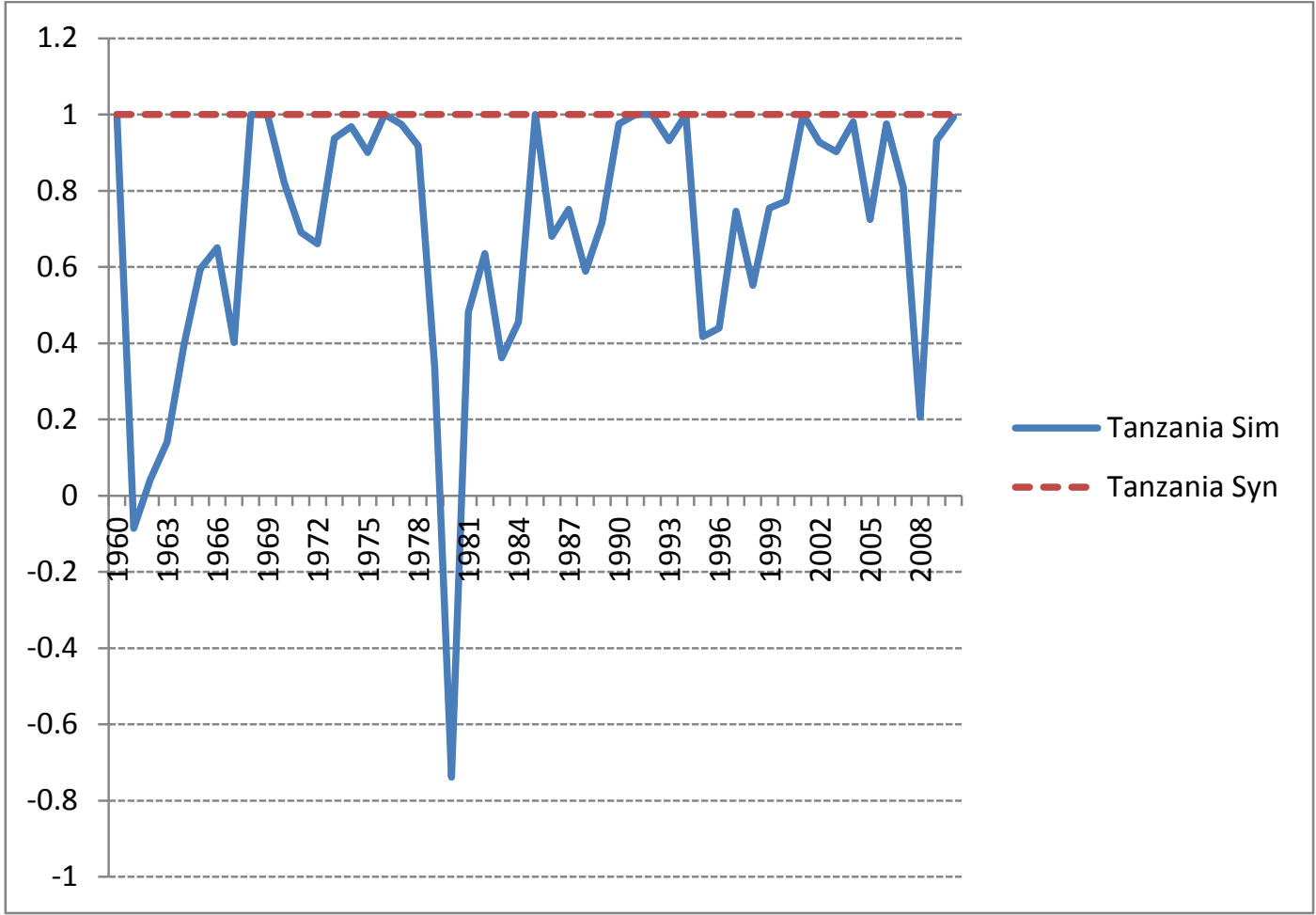

Figure 6. Similarity and Synchronicity for Tanzania

We will thus follow Mink, et al. and test for a break in the aggregate and national similarity series by regressing each on a constant and linear time trend and applying the Andrews-Quandt test. The Andrews-Quandt technique tests for "endogenous" breaks and does not rely on a particular date being specified by the researcher. Like Mink, et al. we do not test for a break in the synchronicity measure, as it is basically a discrete series.

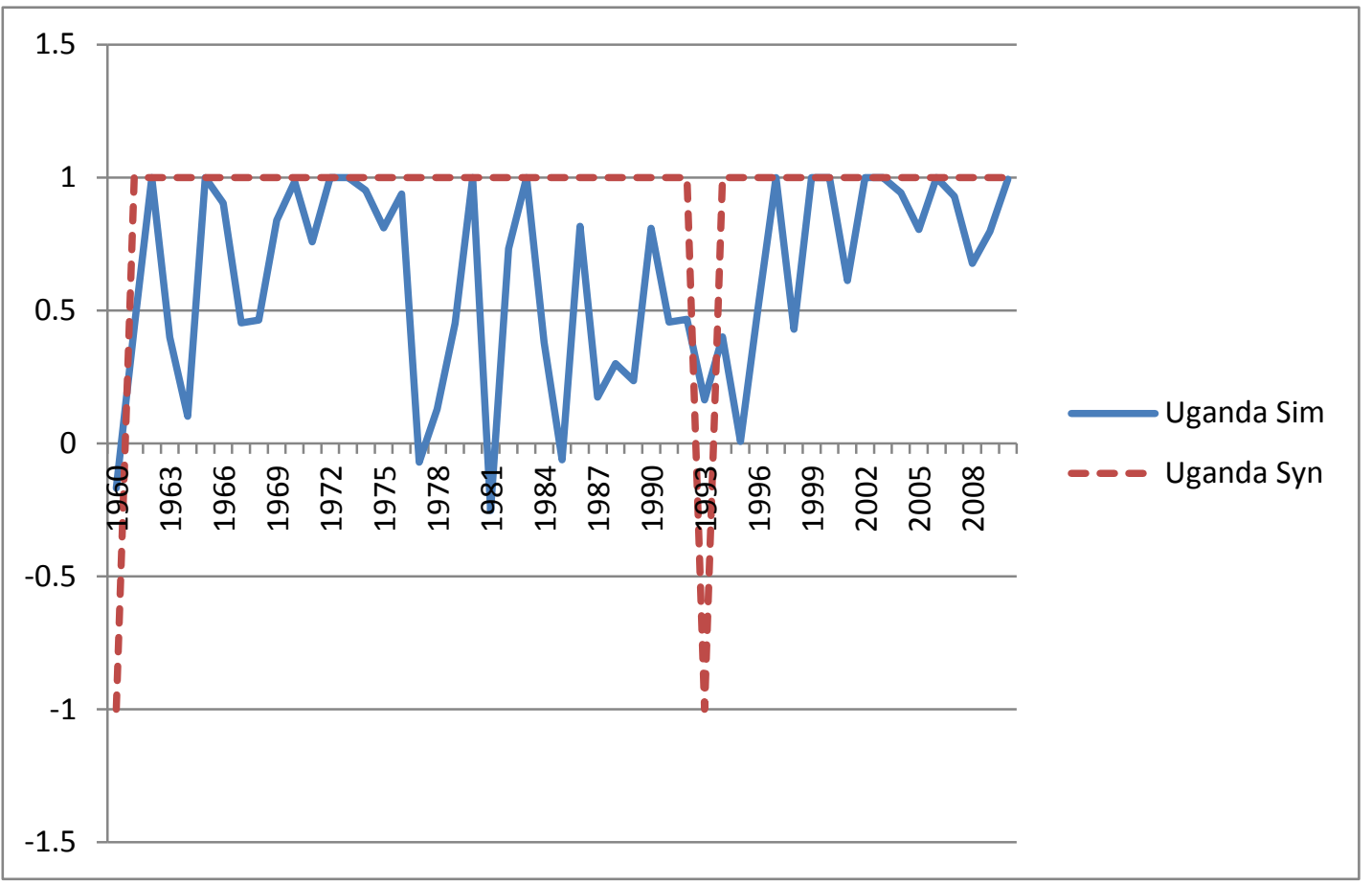

Figure 7. Similarity and Synchronicity for Uganda 
Table 3 displays the results. As shown in the table, Burundi, Kenya and Tanzania display no significant break-the p-values for the Andrews-Quandt test statistics are all very high. The results for Kenya and Tanzania stand in contrast to the results of Kishor and Ssozi-their results indicated an increase in BCS for these two countries toward the end of their sample.

Table 3 Break Test Results

\begin{tabular}{cccc}
\hline & Constant & Trend & AQ Test \\
\hline \multirow{2}{*}{ Burundi } & 0.725 & -0.0018 & 1988 \\
& $(0.000)$ & $(0.5933)$ & $(0.9655)$ \\
Kenya & 0.575 & 0.003 & 1986 \\
& $(0.000)$ & $(0.286)$ & $(0.8374)$ \\
& & & \\
Rwanda & 0.169 & 0.002 & 1992 \\
& $(0.573)$ & $(0.7757)$ & $(0.000)$ \\
Tanzania & 0.464 & 0.006 & 1979 \\
& $(0.0004)$ & $(0.048)$ & $(0.3261)$ \\
Uganda & 0.449 & 0.004 & 1977 \\
& $(0.0015)$ & $(0.17)$ & $(0.0654)$ \\
Total & 0.476 & 0.003 & 1992 \\
& $(0.000)$ & $(0.209)$ & $(0.0935)$ \\
\hline
\end{tabular}

Rwanda has a significant break in 1992. Figure 6 does suggest that there was a major change in similarity in 1992-this metric exhibits a sharp and sustained drop beginning in that year; indeed similarity would remain negative until 1997. The year 1992 was in the middle of the Rwandan Civil War, which may well have had a negative impact on BCS vis-a-vis the other EAC countries.

Uganda displays a break in 1977 that, with a p-value of 0.0654 , is significant at the ten percent level. Possibly, the rule of Idi Amin, which was generating controversy this year as the UK severed diplomatic relations may have been related to this break. Overall similarity had a significant break in 1992. This might have been driven by the turmoil in Rwanda at the time.

What is certain is that none of the similarity series exhibit a break for 2000, or 2005. Thus even if the EAC formed a CU and there was a large effect of this common currency on trade, the higher trade may well not have much effect on improving BCS.

\section{Conclusion}

The results presented here indicate that all five EAC countries have experienced sharp drops in BCS in recent years. Moreover Rwanda exhibits a relatively low level of BCS with other EAC nations. Finally, our Andrews-Quandt test results indicate no palpable effect of the 2000 EAC Treaty or the 2005 customs union. Thus the act of creating the EAC $\mathrm{CU}$, even if it palpably raised trade (which itself is doubtful, see Havranek, 2010) would likely not have much effect on BCS.

None of this suggests that there would be no benefits at all to monetary union for the EAC. However, given the difficulties in the euro zone, as well as the problems emerging markets in Asia and Latin America had during the 1990s with fixed exchange rates, strong caution would seem warranted before creating a CU for these five nations.

\section{References}

Buigut, S., \& Valev, N. (2005). Is the Proposed East African Monetary Union an Optimal Currency Area? A Structural Vector Autoregression Analysis, World Development, 33, 2119-2133. http://dx.doi.org/10.1016/j.worlddev.2005.06.006

Frankel, J., \& Rose, A. (1996). Economic Structure and the Decision to Adopt a Common Currency, Seminar Papers, 611, Stockholm University, Institute for International Economic Studies.

Havranek, T. (2010). Rose Effect and the Euro: Is the Magic Gone? Review of World Economics, 146, $241-261$. http://dx.doi.org/10/1007/s10290-010-0050-1 
Kishor, N., \& Ssozzi, J. (2011). Business Cycle Synchronization in the Proposed East African Monetary Union: An Unobserved Component Approach, Review of Development Economics, 15, 664-675. http://dx.doi.org/ 10.1111/j.1467- 9361.2011.00634.x

Koopman, S., \& Aceveda, J. (2008). Measuring Synchronization and Convergence of Business Cycles for the Euro Area, UK and US, Oxford Bulletin of Economics and Statistics, 70, 23-51. http://dx.doi.org/ 10.1111/j.14680084.2007.00489.x

Miles, W., \& Vijverberg, C. (2014). Did the Classical Gold Standard Increase Business Cycle Synchronization? Evidence from new Measures, Kyklos, 67, 93-115. http://dx.doi.org/10.1111/kykl.12045

Mink, M., Jacobs, J., \& de Haan, J. (2012). Measuring Coherence of Output Gaps with an Application to the Euro Area, Oxford Economic Papers, 64, 217-236. http://dx.doi.org/10.1093/oep/gpr049

Mkenda, B. (2001). Is East Africa an Optimum Currency Area?, University of Gothenberg Department of Economics Working Paper 41.

Mundell, R. (1961). A Theory of Optimum Currency Areas, American Economic Review, 51, 657-665.

Persson, T. (2001). Currency Unions and Trade: How Large is the Treatment Effect?, Economic Policy, 33, $435-448$. http://dx.doi.org/abs/10.1111/1468-0327.00081

United Nations Economic Commission for Africa (2011). Towards a Common Currency in the Eastern African Community (EAC): Issues, Challenges and Prospects.

Willett, T., Permpoon, O., \& Wihlborg, C. (2010). Endogenous OCA Analysis in the Early Euro Experience, World Economy, 33, 851-872. http://dx.doi.org/ 10.1111/j.1467-9701.2010.01268.x

Wolf, N., \& Ritschl, A. (2011). Endogeneity of Currency Areas and Trade Blocs: Evidence from a Natural Experiment, Kyklos, 64, 291-312. http://dx.doi.org/ 10.1111/j.1467-6435.2011.00507.x

$\mathrm{Xu}$, X. (2006). A Currency Union for Hong Kong and Mainland China?, Journal of International Money and Finance, 25, 894-911. http://dx.doi.org/10.1016/j.jimonfin.2006.07.001

\section{(cc) $\mathrm{BY}$}

This work is licensed under a Creative Commons Attribution 3.0 License. 